\title{
PERENCANAAN STRATEGI SISTEM DAN TEKNOLOGI INFORMASI PADA PT. MICROSIS
}

\author{
Henry Antonius E.W. \\ Jurusan Sistem Informasi, Fakultas Ilmu Komputer, Bina Nusantara University \\ Jln. K.H. Syahdan No. 9, Palmerah, Jakarta Barat 11480 \\ haew@binus.edu
}

\begin{abstract}
The purpose of this study is to analyze the company's business processes and make strategic planning and information technology system that is suitable for supporting the goals and vision of the company's mission. The research method is data collection in the form of interviews with the company management and staff, field observations, literature research related to strategic planning and information technology systems. The results of this study prove that the company has a weakness in the implementation of information systems which is not maximized, while the strength of the company has not been fully supported by the use of information technology . This shows that the need for strategic planning and information technology systems to support achievement of business strategy at the company over the next five years. Thus, this research produced a strategic plan in the form of application architecture, hardware architecture, network architecture, organizational development, implementation schedule and cost estimates.
\end{abstract}

Kata kunci: strategic planning, system architecture, business process

\begin{abstract}
ABSTRAK
Tujuan dari penelitian ini adalah menganalisis proses bisnis perusahaan dan membuat perencanaan strategi sistem dan teknologi informasi yang sesuai untuk mendukung tujuan dan visi misi perusahaan. Metode penelitian yang digunakan adalah metode pengumpulan data berupa wawancara dengan pihak perusahaan, observasi, dan juga studi pustaka yang berkaitan dengan perencanaan strategi sistem dan teknologi informasi. Hasil yang dicapai dari penelitian ini membuktikan bahwa perusahaan memiliki kelemahan dalam penerapan sistem informasi yang belum maksimal, sedangkan kekuatan yang dimiliki perusahaan belum secara penuh didukung oleh pemanfaatan teknologi informasi. Hal ini menunjukan bahwa perlu adanya perencanaan strategi sistem dan teknologi informasi untuk mendukung pencapaian strategi bisnis pada perusahaan selama lima tahun kedepan. Sehingga penelitian ini menghasilkan perencanaan strategis dalam bentuk arsitektur aplikasi, arsitektur perangkat keras, arsitektur jaringan: engembangan organisasi, jadwal pengimplementasian serta estimasi biaya.
\end{abstract}

Kata kunci: perencanaan strategis, arsitektur sistem: roses bisnis 


\section{PENDAHULUAN}

Kemajuan-kemajuan dibidang teknologi mendorong banyak perusahaan merencanakan dan menjalankan strategi bisnis perusahaan untuk meningkatkan keunggulan kompetitif perusahaan, maka perusahaan harus mempunyai perencanaan strategi sistem dan teknologi informasi untuk mendukung tercapainya strategi bisnis. Perencanaan strategi sistem dan teknologi informasi merencanakan ke arah mana sistem informasi perusahaan akan dikembangkan. Dengan adanya perencanaan strategi sistem dan teknologi informasi: engembangan sistem informasi dan teknologi informasi: erusahaan menjadi lebih terarah menuju tercapainya strategi bisnis perusahaan. PT. Microsis merupakan perusahaan yang bergerak dibidang IT Solution, dengan semakin berkembangnya teknologi informasi, maka secara tidak langsung akan memberikan pengaruh, baik terhadap produk dan jasa yang ditawarkan maupun pada operasional PT. Microsis. Pengembangan sistem informasi yang lambat dan kurang dapat memenuhi kebutuhan perusahaan mengakibatkan sistem yang digunakan saat ini tidak berfungsi optimal dalam membantu kegiatan operasional perusahaan. Dengan adanya perencanaan strategi sistem dan teknologi informasi yang selaras dengan strategis bisnis perusahaan, diharapkan dapat membantu perusahaan dalam meningkatkan keunggulan bersaing. Implementsi dari perencanaan strategi sistem dan teknologi informasi dapat dilakukan secara bertahap sesuai dengan kebutuhan dan kondisi perusahaan.

\section{METODE}

Perencanaan strategi sistem informasi merupakan sekumpulan tujuan jangka panjang yang menggambarkan kebutuhan sistem dan arsitektur teknologi informasi untuk mencapai tujuan perusahaan (Turban, 2003: 462).

Selain mengetahui Strategi Sistem dan Teknologi Informasi: erlu juga diketahui pemahaman terhadap Strategi Bisnis yang meruapakan arah dari implementasi Strategi Sistem dan Teknologi Informasi. Strategi Bisnis adalah strategi fungsional yang berorientasi pada fungsi-fungsi kegiatan manajemen, misalnya strategi pemasaran, strategi produksi atau operasional, strategi distribusi, strategi organisasi dan strategi-strategi yang berhubungan dengan keuangan dari suatu bisnis (Rangkuti, 2006: 7). Strategi Bisnis berkaitan dengan cara-cara yang digunakan perusahaan untuk mendapatkan keuntungan persaingan didalam setiap bisnis utamanya (Grant, 2002: 14). Perlu diketahui pula bahwa Strategi Bisnis merupakan dokumen yang harus dijadikan landasan berpijak utama dalam pembuatan Strategi Sistem dan Teknologi Informasi karena dalam dokumen tersebut disebutkan visi dan misi perusahaan serta target kinerja masing-masing fungsi pada struktur organisasi (Indrajit, 2001: 31). Dikarenakan perkembangan teknologi yang sangat cepat, kadang kala menyulitkan organisasi dalam menerapkan standar proses perencanaan sistem dan teknologi informasi (Pollack, 2010: 53)

69):

Suatu strategi bisnis biasanya meliputi beberapa hal seperti berikut (Ward dan Peppard, 2002:

- Vission: encapaian dari sebuah misi atau dapat diartikan sebagai sebuah pandangan masa depan dari sebuah bisnis yang menjadi tujuan umum sebuah perusahaan.

- Mission, adalah pernyataan yang memberikan arahan tentang apa yang akan dilakukan oleh sebuah perusahaan dalam mencapai visinya.

- Business Driver, adalah beberapa faktor kritis pendorong perubahan yang dapat memberikan fokus pada bisnis sehingga dapat memenuhi sasarannya. 
- Objectives, adalah sasaran-sasaran yang ditetapkan dan harus dipenuhi oleh perusahaan dalam pencapaian visi perusahaan.

- Strategies, adalah kebijakan atau tindakan langsung yang dipilih perusahaan sebagai alat untuk mencapai tujuan dan memenuhi misinya.

- Critical Success Factors (CSF), adalah beberapa area kunci dimana sesuatu harus berjalan dengan baik sehingga keberhasilan bisnis dapat dicapai.

- Business Area Plans, adalah perencanaan dari berbagai area bisnis yang ada yang berkaitan dengan strategi bisnis perusahaan.

Gambar dibawah mengilustrasikan hubungan antara Strategi Bisnis, Strategi SI dan Strategi TI dalam suatu pendekatan untuk menyusun strategi sistem dan teknologi informasi yang terintegrasi dengan strategi bisnis perusahaan.

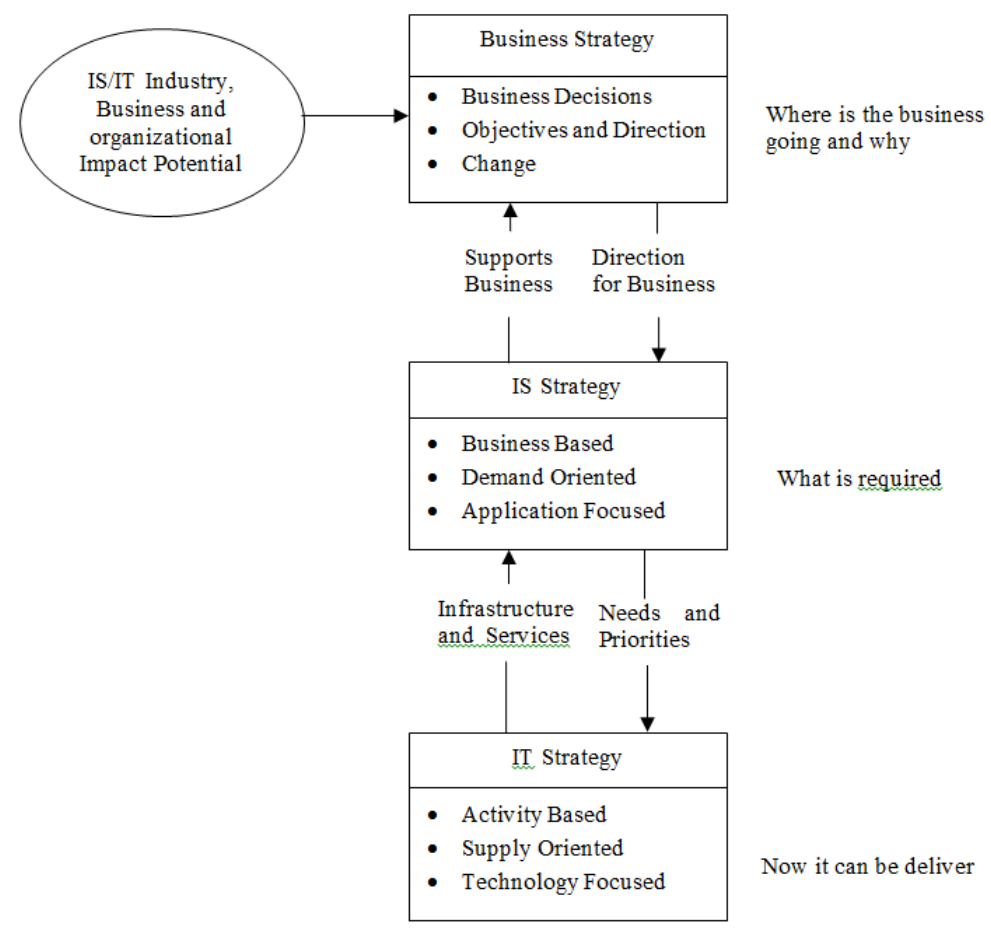

Gambar 1 Hubungan antara Strategi Bisnis, Strategi SI dan Strategi TI

\section{HASIL DAN PEMBAHASAN}

PT. Microsis adalah sebuah perusahaan yang bergerak dalam bidang penjualan dan jasa perbaikan berbagai macam dan merek perangkat keras dan piranti lunak seperti personal computer, notebook: rinter, aplikasi desktop, anti virus, dan lain sebagainya. Perusahaan melakukan penjualan dengan sistem eceran maupun partai dan melayani pelanggan baik dari perusahaan maupun individu serta menggunakan sistem pembayaran secara tunai dan transfer. Dalam kondisi persaingan yang begitu kompetitif, PT. Microsis pun menyadari sepenuhnya untuk lebih fokus dan lebih profesional merupakan hal penting yang harus dilakukan agar dapat memberikan pelayanan yang terbaik bagi pelanggannya.

\section{Strategi Bisnis Perusahaan}

Sebagai perusahaan yang bertujuan untuk memajukan perkembangan bisnisnya: T. Microsis memiliki strategi bisnis dalam mencapai tujuan tersebut. Strategi bisnis PT. Microsis yaitu: 
1. Kerjasama dengan Pemasok

2. Meningkatkan Kualitas Produk dan Jasa

3. Lebih memfokuskan bisnis perusahaan

\section{Analisis Lingkungan Eksternal Bisnis Perusahaan}

Analisis terhadap lingkungan eksternal bisnis perusahaan mencakup analisis terhadap persaingan bisnis perusahaan dengan menggunakan teknik analisis persaingan porter dan analisis PEST.

a) Lima (5) Faktor Persaingan Porter

Berikut ini akan dibahas lingkungan persaingan dari PT. Microsis :

1. Persaingan Industri (Industry Rivalry)

Perusahaan besar menjadi pemasok bagi para perusahaan IT Solution lainnya, seperti PT. Metrodata Electronics, Tbk. Perusahaan ini memiliki keunggulan kompetitif dalam segi pengalaman yang puluhan tahun, keuangan yang kuat, kerjasama dengan pemasok-pemasok besar, dan juga memiliki jaringan terhadap perusahaan-perusahaan besar seperti perusahaan multinasional Badan Usaha Milik Negara atau sektor pemerintahan Indonesia. Sedangkan perusahaan pesaing skala menengah seperti PT. Microsis ialah PT. Daya Transformatika: T. Erakomp Infonusa: T. Alpha Cipta: T. Alpha Graha, dan lain-lain.

2. Ancaman Pendatang Baru (Threat of New Entrants)

Saat ini, banyak perusahaan-perusahaan baru yang muncul dengan keunggulannya masingmasing. Hal ini dapat mengancam keberadaan PT. Microsis, dengan semakin banyaknya perusahaan penyedia IT Solution para pelanggan dapat dengan mudah membandingkan dan memilih perusahaan penyedia IT Solution yang dapat memberikan pelayanan terbaik bagi para pelanggan. Contoh perusahaan pendatang baru dibidang IT Solution seperti PT. Script Intermedia dan PT. Multi Informatika Solusindo.

PT. MIS baru berdiri beberapa tahun, tetapi bisa dilihat dari web nya: T. MIS telah mengembangkan SI/TI di perusahaan nya dengan baik dan lebih maksimal. Kelebihan PT. Multi informatika solusindo adalah bisa mengikuti perkembangan SI/TI dengan menggunakan e-commerce dalam proses penjualan (e-sales) dan pemasaran berbasis web (e-marketing). http://www.multisolusi.com/index.php.

3. Kekuatan Tawar Menawar Pemasok (Bargaining Power of Suppliers)

Bagi perusahaan penyedia jasa TI seperti PT. Microsis, yang menjadi pemasok ialah perusahaan-perusahaan yang menyediakan produk-produk TI, seperti PT. Astrindo Senayasa: T. Hewlett-Packard Indonesia: T. Microsoft Indonesia: T. Datamation Purwana Utama: T. Grafitama Detakreasi Agung: T. Memory Jaya Sakti: T. 21 Camera. Hubungan bisnis antara PT. Microsis dengan perusahaan-perusahaan penyedia produk TI memunculkan suatu hubungan bisnis yang saling menguntungkan, karena Microsis membutuhkan produk TI dari pemasok demi mendukung kelancaran bisnisnya, di samping itu pihak pemasok memperoleh keuntungan dari PT. Microsis. Meskipun begitu, kekuatan tawar menawar PT. Microsis dengan pihak distributor cukup kuat karena saat ini terdapat banyak distributor penyedia produk TI, sehingga PT. Microsis dapat memilih distibutor maupun pemasok yang paling efisien dari segi biaya dan mampu menunjang kegiatan operasional perusahaan.

4. Kekuatan Tawar Menawar Pelanggan (Bargaining Power of Customers)

Bagi perusahaan penyedia jasa TI seperti PT. Microsis, kepuasan pelanggan menjadi hal yang utama. PT. Microsis menganggap bahwa kebutuhan pelanggan harus dapat terpenuhi dengan baik, hal ini untuk menjaga pelanggan lama dan untuk mencari pelanggan baru.

Saat ini, kekuatan tawar menawar PT. Microsis lemah karena terancam oleh tuntutan pelanggan akan kepuasan dalam memperoleh produk dan jasa yang semakin berkembang. Untuk mengatasi ancaman ini: T. Microsis terus belajar dalam mengembangkan kemampuan dalam penguasaan produk dengan cara mengadakan training product knowledge untuk karyawan nya dan kemampuan teknik dari karyawan perusahaan untuk meningkatan kualitas layanan dan memahami kebutuhan pelanggan agar dapat memberikan kepuasan bagi 
pelanggan dan menumbuhkan kepercayaan pelanggan sehingga terus menggunakan jasa PT. Microsis.

5. Ancaman Produk Substitusi (Threat of Subtitute Products)

Produk substitusi yang menjadi ancaman bagi PT. Microsis adalah tenaga-tenaga yang ahli dan kompeten dibidang TI, mereka bekerja secara individu tidak seperti Microsis yang bekerja dalam team. Para tenaga ahli ini tidak terlibat oleh kebijakan suatu perusahaan. Mereka memiliki kelebihan yaitu waktu yang fleksibel dan tarif yang lebih murah, hal ini dapat membuat para pelanggan PT. Microsis beralih untuk menggunakan jasa tenaga ahli ini. Untuk mengantisipasi ancaman-ancaman produk substitusi: T. Microsis membutuhkan pemanfaatan SI/TI dalam pengolahan data-data mengenai produk dan jasa serta memberikan informasi tersebut kepada pelanggan maupun calon pelanggan melalui pemanfaatan teknologi komunikasi yang berkembang saat ini.

\section{b) Analisis PEST Perusahaan}

1. Politik

Kondisi politik Indonesia tidak mempengaruhi bisnis PT. Microsis secara langsung, walaupun terjadi transisi pemerintahan: erubahan undang-undang: ajak, dan peraturan daerah tidak akan memberikan dampak langsung terhadap permintaan bisnis dari para pelanggan PT. Microsis.

Dengan adanya UU ITE: erusahaan seperti PT. Microsis harus dapat mengadaptasi undangundang tersebut, hal ini disebabkan PT. Microsis mempunyai bisnis yang bergerak dalam teknologi informasi, dan juga perusahaan harus tanggap atas hak dan kewajiban yang didapatkan dengan adanya UU ITE.

2. Ekonomi

Situasi Global yang tidak menentu memberikan kekhawatiran kepada para masyarakat dunia: erusahaan-perusahaan lebih berhati-hati dalam mengeluarkan keputusan mengenai pengeluaran. Dengan kondisi sekarang ini, kebutuhan perusahaan akan TI bukan menjadi prioritas utama, hal ini dimaksudkan untuk menghemat anggaran perusahaan. Dan juga harga valas dollar yang naik turun secara tajam dapat mempengaruhi kontrak kerjasama PT. Microsis dengan para pelanggan, khususnya kontrak yang menggunakan mata uang Dollar sebagai mata uang pembayaran.

3. Sosial

PT. Microsis berpegang teguh bahwa pelanggan adalah sahabat sejati sehingga perlu adanya perlakuan khusus yang lebih daripada sekedar hubungan bisnis. Kerjasama dengan pelanggan bukan hanya terletak pada transaksi bisnis semata: T. Microsis secara terbuka menerima setiap permintaan, saran, dan kritik dari pelanggannya.

Perusahaan selalu menjaga agar produk dan jasa yang perusahaan berikan untuk pelanggan, tidak memberi dampak negatif terhadap lingkungan masyarakat. Dengan adanya lingkungan kerja sama yang aman dan nyaman dapat memberikan kesejahteraan baik bagi perusahaan maupun lingkungan disekitarnya.

4. Teknologi

Dengan berkembangnya teknologi yang semakin pesat mengharuskan perusahaan untuk dapat sigap dalam beradaptasi. Selain itu dengan perkembangan teknologi yang begitu cepat dapat mempengaruhi kinerja suatu perusahaan, saat ini banyak perusahaan yang berhasil untuk menerapkan perkembangan teknologi sebagai penunjang kegiatan bisnis perusahaan, bahkan banyak perusahaan lain yang telah menerapkan perkembangan teknologi sebagai strategi untuk menciptakan suatu keunggulan kompetitif .

\section{Analisis Lingkungan Internal Bisnis Perusahaan}

Analisis terhadap lingkungan internal bisnis perusahaan mencakup analisis terhadap rantai nilai perusahaan (Value Chain Service Business), analisis SWOT (Strength, Weakness, Opportunity, Threat), analisis CSF (Critical Success Factor) \& KPI (Key Performance Indicator).

a) Analisis SWOT Perusahaan 
Analisis SWOT membandingkan antara faktor eksternal peluang dan ancaman dengan faktor internal kekuatan dan kelemahan, sehingga perusahaan dapat memahami dan mengenali kondisikondisi dari SWOT untuk mendukung proses formulasi strategi.

Tabel 1 Matriks SWOT pada PT. Microsis

\begin{tabular}{|c|c|c|}
\hline EFAS & $\begin{array}{l}\text { Strength ( S ) } \\
\text { (S1) Kemampuan technical } \\
\text { support yang cepat beradaptasi } \\
\text { dan tanggap dalam } \\
\text { menyelesaikan } \\
\text { pelanggan } \\
\text { (S2) Pengalaman perusahaan } \\
\text { selama belasan tahun di bidang } \\
\text { IT Solution. } \\
\text { (S3) Adanya jaminan mutu, } \\
\text { kualitas dan garansi untuk } \\
\text { produk dan jasa. } \\
\text { (S4) Adanya loyalitas dari } \\
\text { pelanggan potensial perusahaan }\end{array}$ & $\begin{array}{l}\text { Weakness ( W ) } \\
\text { (W1) Belum adanya } \\
\text { pemanfaatan website sebagai } \\
\text { sarana promosi dan menjaga } \\
\text { hubungan dengan pelanggan. } \\
\text { (W2) Kesulitan perusahaan } \\
\text { untuk memenuhi kebutuhan } \\
\text { pelanggan yang berada diluar } \\
\text { jangkau. } \\
\text { (W3)Turn Over pengawai } \\
\text { yang cepat. }\end{array}$ \\
\hline Opportunies ( 0 ) & Strategi SO & Strategi WO \\
\hline $\begin{array}{l}\text { (O1) Peningkatan } \\
\text { Teknologi(computer, internet, } \\
\text { komunikasi) yang semakin } \\
\text { pesat. } \\
\text { (O2) Kebutuhan pelanggan } \\
\text { yang semakin lama semakin } \\
\text { bertambah terhadap teknologi } \\
\text { informasi. } \\
\text { (O3) Terbukanya Kerjasama } \\
\text { dengan SMK unggulan } 7 \\
\text { Semarang. } \\
\text { (O4) Adanya permintaan } \\
\text { produk dan jasa dari } \\
\text { pelanggan yang berasal dari } \\
\text { daerah lain. }\end{array}$ & $\begin{array}{l}\text { (S1-O1) Mengadakan pelatihan- } \\
\text { pelatihan dimaksudkan untuk } \\
\text { meningkatkan kualitas serta } \\
\text { pengetahuan SDM mengenai } \\
\text { produk dan jasa TI. } \\
\text { (S2-O2) memberikan solusi } \\
\text { terbaik untuk pelangan dengan } \\
\text { memberikan informasi } \\
\text { mengenai pencapaian, track } \\
\text { record, dan keahlihan } \\
\text { perusahaan } \\
\text { (S4-O4) Bekerjasama dengan } \\
\text { pemasok yang berada diluar } \\
\text { jangkauan perusahaan. }\end{array}$ & $\begin{array}{l}\text { (W1-O1) Membuat website } \\
\text { sebagai sarana e-marketing } \\
\text { untuk memasarkan produk } \\
\text { maupun jasa dan juga sebagai } \\
\text { bagi pelanggan. } \\
\text { (W2-O2) Bekerjasama } \\
\text { dengan pesaing yang berada } \\
\text { diluar jangkauan perusahaan. } \\
\text { (W2-O4) Membuka cabang } \\
\text { perusahaan. Dengan adanya } \\
\text { cabang perusahaan dapat } \\
\text { lebih mudah untuk } \\
\text { memenuhi kebutuhan } \\
\text { pelanggan yang berada diluar } \\
\text { jangkauan dan kebutuhan } \\
\text { pelanggan yang semakin } \\
\text { lama bertambah akan TI pun } \\
\text { dapat terpenuhi. } \\
\text { (W3-O3) kerjasama dengan } \\
\text { SMK } 7 \text { semarang untuk } \\
\text { penyediaan sumber daya } \\
\text { manusia yang kompeten }\end{array}$ \\
\hline $\begin{array}{l}\text { Threats ( T ) } \\
\text { (T1) Munculnya tenaga-tenaga } \\
\text { yang ahli dan kompeten yang } \\
\text { berdiri sendiri. } \\
\text { (T2) Mudahnya pemain baru } \\
\text { untuk masuk ke dalam pasar } \\
\text { IT Solution. }\end{array}$ & $\begin{array}{l}\text { Strategi ST } \\
\text { (S1-T1) Memberikan informasi } \\
\text { dan jaminan mengenai kualitas } \\
\text { technical support } \\
\text { (S3-T2) Memberikan informasi } \\
\text { yang jelas tentang produk serta } \\
\text { kerjasama dengan distributor } \\
\text { resmi yang memberikan jaminan } \\
\text { garansi }\end{array}$ & $\begin{array}{l}\text { Strategi WT } \\
\text { (W3-T2) perekrutan tenaga- } \\
\text { tenaga ahli dan kompeten } \\
\text { untuk memenuhi kebutuhan } \\
\text { sumber daya manusia } \\
\text { khususnya bagian yang } \\
\text { berhubungan dengan SI/TI. }\end{array}$ \\
\hline
\end{tabular}

b) Analisis Value Chain Service Bussines (Value Shop) 


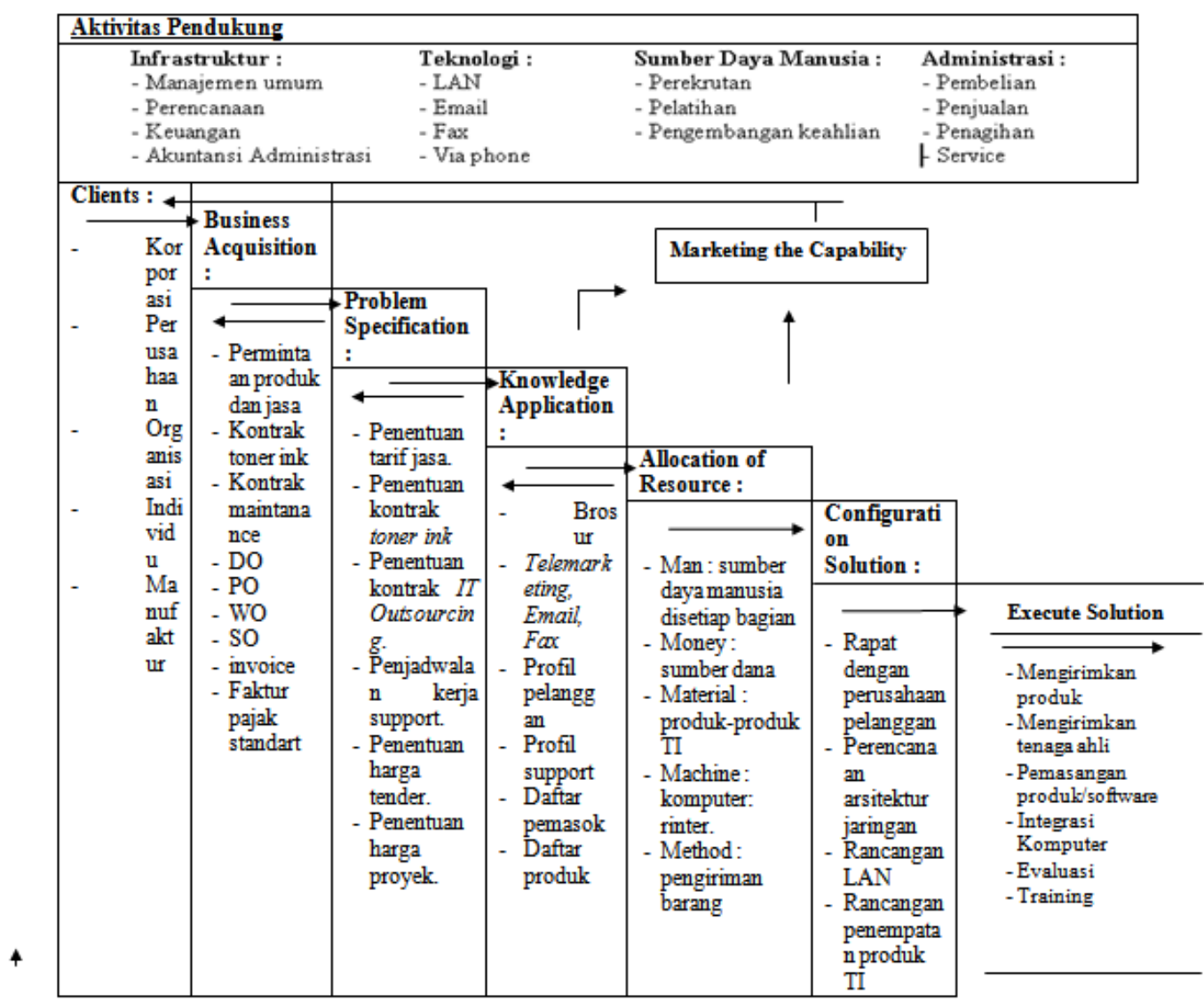

c) Analisis CSF (Critical Success Factor) dan KPI (Key Performance Indicator) Perusahaan. Adapun CSF dan KPI pada PT. Microsis akan diuraikan pada tabel sebagai berikut:

Tabel 2 CSF - KPI PT. Microsis

\begin{tabular}{|c|c|c|}
\hline Objectives & CSF & KPI \\
\hline 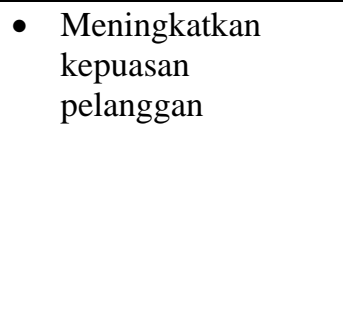 & $\begin{array}{l}\text { - } \text { Memberikan informasi secara } \\
\text { cepat, akurat dan tepat } \\
\text { kepada pelanggan } \\
\text { - Meningkatkan kemampuan } \\
\text { support dalam melayani } \\
\text { pelanggan. } \\
\text { - Memberikan produk dan jasa } \\
\text { yang berkualitas }\end{array}$ & $\begin{array}{l}\text { - Informasi ter-update yang dapat } \\
\text { diakses setiap saat. } \\
\text { - Pelatihan support minimal } \\
\text { sebulan } 2 \text { kali. } \\
\text { - Adanya jaminan terhadap produk } \\
\text { dan jasa yang ditawarkan }\end{array}$ \\
\hline $\begin{array}{l}\text { - Meningkatkan } \\
\text { kinerja operasional } \\
\text { perusahaan }\end{array}$ & $\begin{array}{l}\text { - Mempersingkat waktu yang } \\
\text { dibutuhkan untuk memproses } \\
\text { sebuah transaksi. } \\
\text { - Mengelola data transaksi } \\
\text { secara tepat }\end{array}$ & $\begin{array}{l}\text { - Pembuatan bukti transaksi yang } \\
\text { berlangsung dengan cepat } \\
\text { - Tidak ada kesalahan dalam } \\
\text { pencatatan data transaksi }\end{array}$ \\
\hline $\begin{array}{l}\text { - Menghadapi } \\
\text { persaingan }\end{array}$ & $\begin{array}{l}\text { - } \text { Memberikan standart } \\
\text { pelayanan yang berkualitas } \\
\text { - } \text { Memberikan harga yang } \\
\text { kompetitif sesuai dengan } \\
\text { kualitas pelayanan }\end{array}$ & $\begin{array}{l}\text { - } \text { Berkurangnya keluhan dari } \\
\text { pelanggan sebesar } 30 \% \\
\text { - Harga produk dan jasa } \\
\text { perusahaan lebih murah sesuai } \\
\text { dibandinkan harga pesaing }\end{array}$ \\
\hline
\end{tabular}




\begin{tabular}{lll}
\hline Memperluas & $\bullet \begin{array}{l}\text { Memiliki jaringan yang dapat } \\
\text { menjangkau pelanggan }\end{array}$ & $\begin{array}{l}\text { Dapat memperluas pasar sampai } \\
\text { daerah jabodetabek }\end{array}$ \\
\hline
\end{tabular}

\section{Analisis Lingkungan Eksternal SI/TI Perusahaan}

Dengan berkembangnya teknologi secara langsung dan tidak langsung akan mempengaruhi bisnis dari perusahaan, sistem electronic commerce yang banyak diterapkan oleh perusahaan sejenisnya dapat memberikan dampak yang besar dalam perubahan bisnis perusahaan. Dengan ecommerce perusahaan dapat mengembangkan strategi pemasaran, strategi penjualan, dan juga pelayanan pelanggan. Saat ini teknologi berkembang dengan saat pesat, hampir setiap bulan bahkan dalam hitungan minggu atau hari para produsen software maupun hardware meliris produk terbaru, belum lagi perkembangan dari teknologi jaringan serta inovasi penggunaan teknologi informasi pada semua aspek bisnis. PT. Microsis tidak boleh terpaku mengikuti perkembangan teknologi sebagai penguasaan speksifikasi produk dan jasa yang ditawarkan, tetapi perusahaan harus mampu menerapkan perkembangan yang ada untuk mengatasi masalah yang ada serta memperkuat posisi dalam persaingan bisnis yang ketat.

\section{Analisis Lingkungan Internal SI/TI Perusahaan}

a) Spesifikasi Hardware dan Software Perusahaan

Tabel 3 Spesifikasi Hardware dan Software pada PT. Microsis

\begin{tabular}{|c|c|c|}
\hline Jenis & Keterangan & Jumlah \\
\hline \multirow[t]{11}{*}{ Hardware } & $\begin{array}{ll}\text { PC Desktop Eksekutif : } \\
\text { - } & \text { Processor Intel Pentium IV } \\
\text { - } & \text { Memory } 512 \text { MB DDR } \\
\text { - } & \text { Hard disk } 40 \text { GB } \\
\text { - } & \text { Monitor LCD } 15 \\
\text { - } & \text { LAN card } \\
\end{array}$ & 3 \\
\hline & $\begin{array}{l}\text { Laptop Desktop Eksekutif : } \\
\text { - Processor Intel Centrino core2duo } \\
\text { - Memory } 1 \text { GB DDR2 } \\
\text { - Hard disk } 120 \text { GB } \\
\text { - LCD 14,1', }\end{array}$ & 2 \\
\hline & $\begin{array}{l}\text { PC Desktop Staff : } \\
\text { - Processor Intel Pentium IV } \\
\text { - Memory } 512 \text { MB SDRAM } \\
\text { - Hard disk } 80 \text { GB } \\
\text { - Monitor CRT 15” } \\
\text { - LAN card }\end{array}$ & 10 \\
\hline & $\begin{array}{l}\text { Database Server : } \\
\text { - } \quad \text { Processor Intel Xeon 2,8 GHz } \\
\text { - } \quad \text { Memory } 4 \text { GB DDR2 } \\
\text { - } \quad \text { Hard disk } 250 \mathrm{~GB} \\
\text { - } \quad \text { LAN card }\end{array}$ & 1 \\
\hline & Printer Server & 1 \\
\hline & Printer & 3 \\
\hline & Server UPS & 1 \\
\hline & Server CCTV & 1 \\
\hline & CCTV & 7 \\
\hline & Switch / hub & 2 \\
\hline & Modem Router & 1 \\
\hline
\end{tabular}




\begin{tabular}{ll}
\hline Software & - Genuine Microsoft Windows XP \\
& - Genuine Microsoft Windows Vista \\
& - Genuine Microsoft Office 2003 \\
& - Antivirus Avg Free \\
\hline Aplikasi & - Aplindows Server 2003 Keuangan (Accurate) \\
\hline
\end{tabular}

b) Arsitektur Jaringan Perusahaan

Berikut adalah gambar dari infrastruktur jaringan pada PT. Microsis:

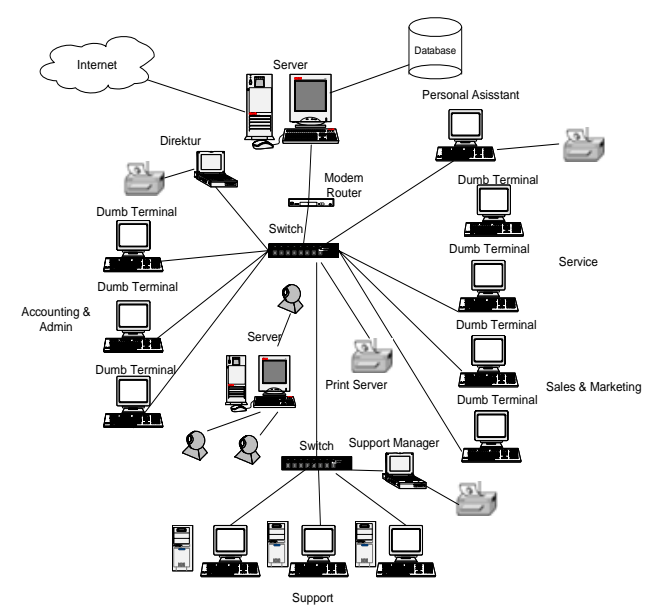

Gambar 3 Arsitektur Jaringan pada PT. Microsis

c) Aplikasi Portfolio Perusahaan

Berikut adalah aplikasi portfolio saat ini pada PT. Microsis :

Tabel 4 Analisis Aplikasi Portofolio saat ini pada PT. Microsis

\begin{tabular}{|c|c|}
\hline Strategic & High Potential \\
\hline & \\
\hline Key Operational & Support \\
\hline & Aplikasi Accounting (Accurate) \\
\hline
\end{tabular}

\section{Proses Strategi SI/TI}

a) Dari hasil analisis PEST didapatkan beberapa kesimpulan:

1. Kebutuhan akan informasi yang cepat dan akurat

2. Perkembangan teknologi yang semakin pesat

3. Munculnya UU ITE yang dapat memberikan keuntungan bagi perusahaan

4. Perusahaan harus lebih memperhatikan hubungan dengan pihak yang terkait dengan perusahaan baik dengan karyawan: elanggan, maupun dengan pemasok.

b) Dari hasil analisis 5 Persaingan Porter didapatkan beberapa kesimpulan:

1. Persaingan dalam bisnis IT Solution yang semakin ketat

2. Perusahaan tergantung oleh loyalitas pelanggan

3. Pola pikir pelanggan yang menginginkan kualitas produk yang tinggi dengan harga yang rendah

c) Dari hasil analisis value chain service bussines didapatkan beberapa kesimpulan: 
1. Data-data dan operational perusahaan sudah terkomputerisasi dengan baik tetapi tidak dalam semua bidang.

2. Pemasaran masih bersifat tradisional (telemarketing, brosur)

3. Sumber daya informasi yang kurang dalam mendukung pengambilan keputusan dan pemecahan masalah.

4. Kurangnya knowledge application dalam perusahaan

d) Dari hasil analisa CSF dan KPI didapatkan beberapa kesimpulan:

1. Perusahaan memiliki tujuan dan sasaran yang jelas mengenai hal yang harus dilakukan untuk memenangkan persaingan.

2. Kualitas produk dan jasa yang ditawarkan, serta upaya pemenuhan kepuasan pelanggan merupakan hal yang ingin dicapai oleh perusahaan

e) Dari hasil analisa Portfolio aplikasi didapatkan beberapa kesimpulan:

1. Perusahaan hanya memiliki Sistem Informasi Akuntansi

2. SIA PT. Microsis merupakan aplikasi paket yang kurang dapat memenuhi kebutuhan bisnis perusahaan di masa mendatang.

3. PT. Microsis membutuhkan sistem informasi yang dapat mendukung semua fungsi di perusahaan dan juga dapat mendukung bisnis khususnya pada masa mendatang.

f) Dari hasil analisa SWOT didapatkan beberapa kesimpulan:

1. PT. Microsis memiliki keunggulan serta peluang yang besar dalam bisnis IT Solution

2. PT. Microsis memiliki ancaman besar dari para pesaing, tetapi dapat diatasi dengan memberikan jaminan kualitas produk dan layanan yang maksimal

3. Kelemahan yang harus diatasi ialah kurangnya pemanfaatan sistem informasi dan TI untuk penjualan: emasaran dan layanan kepada pelanggan.

\section{Usulan Strategi SI/TI}

a) Perancangan ulang arsitektur jaringan dan aplikasi pada PT. Microsis

b) Penerapan e-commerce

c) Penerapan e-business dan aplikasi pendukungnya

Berikut adalah aplikasi $e$-business yang diusulkan, meliputi:

1. Penerapan Electronics Customer Relationship Management (E-CRM)

2. Penerapan Management Information System (MIS)

3. Penerapan Executive Information Systems (EIS)

4. Penerapan Entreprise Application Integration (EAI)

5. Penerapan Survey System

\section{Strategi SI}

a) E-Commerce

Tabel 5 Aplikasi E-Commerce

\begin{tabular}{ll}
\hline \multicolumn{1}{c}{ Aplikasi } & \multicolumn{1}{c}{ E-Commerce(electronic commerce) } \\
\hline Teknologi & Untuk E-Commerce membutuhkan teknologi seperti internet server, web \\
& server(Apache), web browser(mozzila, Firefox) sebagai saluran komunikasi. \\
& Dan juga E-Commerce membutuhkan teknologi standar untuk operasinya \\
& seperti Operating System(Windows XP), Database(Windows Server 2003) \\
& Bahasa pemrograman seperti HTML, XML, dan Java \\
\hline Estimasi Waktu & $\begin{array}{l}\text { Pembangunan aplikasi E-Commerce dimulai pada bulan Januari 2010 dan } \\
\text { diperkirakan selesai bulan Juni 2010. }\end{array}$ \\
\hline
\end{tabular}




$\begin{array}{ll}\text { Manfaat } & \text { Dengan adanya layanan website secara online, diharapkan pelanggan lebih } \\ & \text { mudah dalam melakukan transaksi dengan perusahaan. Akses informasi } \\ & \text { yang cepat dan akurat serta tidak terbatas kapan pun dan dimana pun dengan } \\ & \text { adanya internet. Perusahaan juga mampu untuk meningkatkan pemasaran } \\ & \text { secara interaktif serta layanan dengan memberikan informasi mengenai } \\ & \text { profil pelanggan: roduk: emasok serta layanan yang diberikan oleh PT. } \\ & \text { Microsis }\end{array}$

b) Survey System

Tabel 6 Aplikasi Survey System

\begin{tabular}{|c|c|}
\hline Aplikasi & $\begin{array}{l}\text { Survey System } \\
\end{array}$ \\
\hline Teknologi & $\begin{array}{l}\text { Survey system membutuhkan teknologi operating system seperti: } \\
\text { • } \quad \text { Operating system Windows Xp } \\
\text { • } \quad \text { prosesor Pentium, Celeron dengan minimum ram 64MB RAM }\end{array}$ \\
\hline Estimasi Waktu & $\begin{array}{l}\text { Pembangunan aplikasi Survey system dimulai pada bulan Juli } 2010 \text { dan } \\
\text { diperkirakan selesai bulan September } 2010\end{array}$ \\
\hline Manfaat & $\begin{array}{l}\text { Dengan Survey System: erusahaan dapat mengumpulkan } \\
\text { data-data mengenai kepuasan pelanggan serta mengolahnya } \\
\text { menjadi suatu informasi yang berguna bagi evaluasi kinerja } \\
\text { dari karyawan dan perusahaan. Aplikasi ini menitik-beratkan } \\
\text { pada rincian pelanggan yang akan diolah menggunakan } \\
\text { system riset secara kreatif, sehingga hasil yang diberikan juga } \\
\text { akan kreatif dan mudah dimengerti oleh perusahaan. }\end{array}$ \\
\hline
\end{tabular}

c) E-Customer Relationship Management (CRM)

Tabel 7 Aplikasi E-CRM

\begin{tabular}{ll}
\multicolumn{1}{c}{ Aplikasi } & \multicolumn{1}{c}{ E-CRM (electronic-customer relationship management) } \\
\hline Teknologi & Untuk E-CRM membutuhkan teknologi seperti internet server, web \\
& server(Apache), web browser(mozzila, Firefox) sebagai saluran \\
komunikasi. Dan juga E-CRM membutuhkan teknologi standart untuk \\
operasinya seperti Operating System (Windows XP), Database(Windows \\
Server 2003)
\end{tabular}

d) Management Information System (MIS) 


\begin{tabular}{ll}
\hline \multicolumn{1}{c}{ Aplikasi } & \multicolumn{1}{c}{ Management Information System (MIS) } \\
\hline Teknologi & Untuk Management Information System (MIS)membutuhkan teknologi \\
& seperti Komputer, server, database, web server(Apache), web \\
& browser(mozzila, Firefox), jaringan LAN, intranet, dan internet sebagai \\
& saluran komunikasi. Dan juga Management Information System \\
& (MIS)membutuhkan teknologi standart untuk operasinya seperti Operating \\
& System(Windows XP), Database(Windows Server 2003) \\
\hline Estimasi Waktu & $\begin{array}{l}\text { Pembangunan aplikasi Management Information System (MIS) dimulai } \\
\text { pada bulan Juni 2010 dan diperkirakan selesai bulan Juli 2013 }\end{array}$ \\
\hline Manfaat & MIS terutama melayani fungsi perencanaan: engendalian,dan \\
& pengambilan keputusan di tingkat manajemen \\
& MIS merangkum dan melaporkan operasi-operasi dasar dari \\
& perusahaan \\
MIS biasanya melayani manajer yang tertarik pada hasil-hasil \\
mingguan, bulanan, dan tahunan
\end{tabular}

Management Information System terdiri dari :

1. Sistem Informasi Akuntansi

2. Sistem Informasi Penjualan

3. Sistem Informasi Pembelian

4. Sistem Informasi Persediaan

e) Executive Information System (EIS)

Tabel 9 Aplikasi EIS

\begin{tabular}{ll}
\hline \multicolumn{1}{c}{ Aplikasi } & \multicolumn{1}{c}{ Executive Information System (EIS) } \\
\hline Teknologi & Untuk Executive Information System (EIS) membutuhkan teknologi seperti \\
& Komputer, server, database, web server(Apache), web browser(mozzila), \\
& jaringan LAN, intranet, dan internet sebagai saluran komunikasi. Dan juga \\
& Executive Information System (EIS)membutuhkan teknologi standart untuk \\
& operasinya seperti Operating System(Windows XP), Database(Windows \\
& Server 2003) \\
\hline Estimasi Waktu & Pembangunan aplikasi Executive Information System (EIS) dimulai pada \\
& bulan Januari 2014 dan diperkirakan selesai bulan Juni 2014 \\
\hline Manfaat & 1. Membantu dalam menentukan visi perusahaan \\
& 2. Membantu didalam perencanaan strategis \\
& 3. Membantu didalam pembentukan struktur organisasi \\
& 4. Membantu didalam pengendalian strategic \\
& 5. Mendukung didalam manajemen krisis \\
\hline
\end{tabular}

f) Entreprise application integration(EAI)

EAI atau Entreprise application integration adalah suatu software yang digunakan untuk menghubungkan aplikasi $e$-business seperti MIS, EIS dan CRM. Software ini menyediakan fasilitas konversi dan koordinasi data, komunikasi, aplikasi, dan layanan pesan, serta akses ke berbagai interface aplikasi. Jadi, software EAI dapat mengintegrasikan berbagai kelompok aplikasi perusahaan dengan memungkinkan aplikasi-aplikasi tersebut untuk bertukar data.

\section{Strategi Manajemen SI/TI}

Strategi yang menjamin konsistensi kebijakan yang diambil oleh pihak manajemen yang berkaitan dengan sistem dan teknologi informasi yang akan diimplementasikan oleh perusahaan. 
Kebijakan tersebut berupa struktur organisasi yang dapat mendukung sistem informasi perusahaan, kebijakan investasi perusahaan, dan kebijakan yang berkaitan dengan sumber daya manusia yang berkaitan dengan sistem informasi perusahaan.

a) Bagian pengembangan dan pemeliharaan SI/TI ( IS/IT Development and Maintanance )

b) Bagian pengembangan Website ( Web development )

c) Bagian Administrator Database ( Database Administrator )

d)

\section{Strategi TI}

Strategi TI akan membahas mengenai teknologi informasi yang akan berubah dan apa yang menyebabkan dasar perubahan tersebut. Seperti kita ketahui PT. Microsis menerapkan teknologi informasi untuk menciptakan proses bisnis yang efisien dan efektif, hal ini dimaksudkan agar proses bisnis dapat berjalan baik serta menekan pengeluaran operasional perusahaan. Salah satu usulan rekomendasi strategi TI agar perusahaan dapat menerapkan strategi TI sekaligus menekan biaya strategi TI adalah pemanfaatan teknologi Dump Terminal. Teknologi ini memungkinkan perusahaan untuk menggunakan komputer sebanyak 10-30 PC dengan satu buah CPU saja. Dengan teknologi ini perusahaan dapat menghemat biaya pembelian hardware khususnya CPU.

\section{Rekomendasi Arsitektur Jaringan}

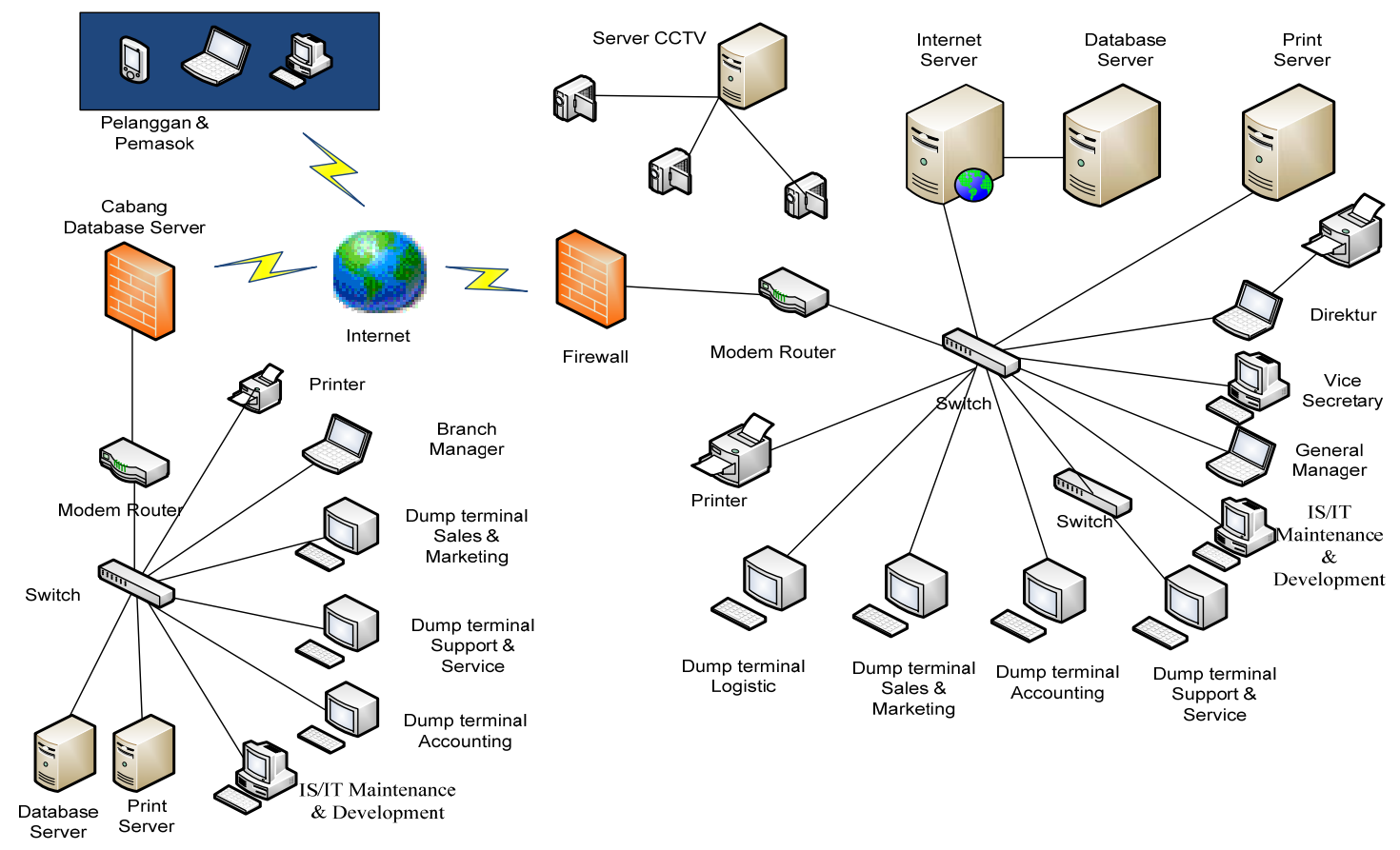

Gambar 4 Rekomendasi Arsitektur jaringan

\section{Rekomendasi Dukungan Hardware}

Berdasarkan analisa lingkungan internal SI/TI pada PT. Microsis, maka perusahaan disarankan untuk menambah atau meng-upgrade berberapa perangkat keras dari sistem yang sedang berjalan saat ini. Hal ini dimaksud untuk mendukung kinerja perusahaan dari segi operasional, taktis, sampai level strategis. Dan semua level itu diharapkan dapat sejalan dengan perencanaan strategi sistem dan teknologi informasi yang direncanakan 
Tabel 10 Rekomendasi Teknologi

\begin{tabular}{|c|c|c|}
\hline Teknologi & Spesifikasi & Jumlah \\
\hline Desktop & $\begin{array}{l}\text { - Intel Core } 2 \text { duo E2200 2,2 GHZ } \\
\text { - Motherboard } \\
\text { - Harddisk SataII 160Gb } \\
\text { - Memory DDR2 1024GB } \\
\text { - Optical Drive DVD-RW } \\
\text { - Lan Card 10/100/1000 Mbps } \\
\text { - Monitor LCD 17” }\end{array}$ & 4 \\
\hline Notebook & $\begin{array}{l}\text { - Intel Core to duo T3200 2,0 GHZ } \\
\text { - Harddisk SataII 160Gb } \\
\text { - Memory DDR2 1024GB } \\
\text { - Optical Drive DVD-RW } \\
\text { - Lan Card 10/100/1000 Mbps }\end{array}$ & 2 \\
\hline Monitor LCD & - Samsung 732NW & 12 \\
\hline Host Computer & $\begin{array}{l}\text { - Intel Xeon Dual Core } 3065 \text { (2.33Ghz) } \\
\text { 1333M,C4Mb } \\
\text { - Harddisk SataII 160Gb } \\
\text { - Memory DDR2 1024GB } \\
\text { - Optical Drive DVD-RW } \\
\text { - Lan Card 10/100/1000 Mbps } \\
\text { - Fast Ethernet switch 100Base-TX }\end{array}$ & 2 \\
\hline $\begin{array}{l}\text { Terminal } \\
\text { Computer }\end{array}$ & NComputing L230 & 12 \\
\hline Database server & $\begin{array}{l}\text { - Intel dual Xeon } 5405 \text { 2,0 GHZ } \\
\text { - Memory DDR2 2*2.048 MB ECC } \\
\text { - Harddisk 500GB Cache 32MB SATA II } \\
\text { - 2x Intel Gigabit NIC 10/100/1000 } \\
\text { - PSU 800W }\end{array}$ & $\begin{array}{l}1 \\
1 \\
1 \\
1 \\
1\end{array}$ \\
\hline Internet server & $\begin{array}{l}\text { - Intel dual Xeon } 5405 \text { 2,0 GHZ } \\
\text { - Memory DDR2 2*2048 MB ECC } \\
\text { - Harddisk 500GB Cache 32MB SATA II } \\
\text { - 2x Intel Gigabit NIC 10/100/1000 } \\
\text { - PSU 800W }\end{array}$ & $\begin{array}{l}1 \\
1 \\
1 \\
1 \\
1\end{array}$ \\
\hline Router & - 4 port 10/100 dan Print server & 2 \\
\hline Modem & $\begin{array}{l}\text { - } 1 \text { x RJ-45 } \\
\text { - } 1 \text { x 2-contact clip type terminal } \\
\end{array}$ & 2 \\
\hline Switch & - 16 Port 10/100 Ethernet & 3 \\
\hline
\end{tabular}

\section{Perencanaan Biaya}

Perencanaan biaya adalah perencanaan strategi sistem dan teknologi informasi berdasarkan kebutuhan biaya didalam pengadaan serta penambahan infrastruktur maupun aset teknologi dan juga kebutuhan biaya didalam pengembangan sistem informasi. Berikut rincian mengenai biaya pengadaan dan upgrade PC / desktop, notebook, server dan aplikasi.

a) Rincian Perkiraan Biaya Usulan Hardware

Tabel 2 Perkiraan Pembelian Teknologi

\begin{tabular}{lccc}
\hline \multicolumn{1}{c}{ Teknologi } & Jumlah & Harga(\$) & Biaya(\$) \\
\hline PC/desktop & 4 & $\$ 500$ & $\$ 2.000$ \\
- Intel Core 2 duo E2200 2,2 GHZ & & & \\
- Motherboard Asus & & & \\
- Harddisk SataII 160Gb & & \\
\hline
\end{tabular}




\begin{tabular}{|c|c|c|c|}
\hline $\begin{array}{l}\text { - Memory DDR2 1024GB } \\
\text { - Optical Drive DVD-RW } \\
\text { - Lan Card 10/100/1000 Mbps } \\
\text { - Monitor LCD 17” }\end{array}$ & & & \\
\hline $\begin{array}{l}\text { Notebook } \\
\text { - Intel Core to duo T3200 2,0 GHZ } \\
\text { - } \text { Harddisk SataII 160Gb } \\
\text { - } \text { Memory DDR2 1024GB } \\
\text { - Optical Drive DVD-RW } \\
\text { - } \text { Lan Card 10/100/1000 Mbps } \\
\end{array}$ & 2 & $\$ 700$ & $\$ 1,400$ \\
\hline $\begin{array}{l}\text { Monitor LCD } \\
\text { - Samsung 732NW }\end{array}$ & 12 & $\$ 150$ & $\$ 1,800$ \\
\hline $\begin{array}{l}\text { Host Computer } \\
\text { - Intel Xeon Dual Core } 3065 \text { (2.33Ghz) } \\
\text { 1333M,C4Mb } \\
\text { - Harddisk SataII 160Gb } \\
\text { - Memory DDR2 1024GB } \\
\text { - Optical Drive DVD-RW } \\
\text { - Lan Card 10/100/1000 Mbps } \\
\text { - Fast Ethernet switch 100Base-TX }\end{array}$ & 2 & $\$ 600$ & $\$ 1,200$ \\
\hline $\begin{array}{l}\text { Office Station } \\
\text { NComputing L230 }\end{array}$ & 12 & $\$ 120$ & $\$ 1,440$ \\
\hline $\begin{array}{l}\text { Server } \\
\text { - Intel dual Xeon } 5405 \text { 2,0 GHZ } \\
\text { - Memory DDR2 2*2048 MB ECC } \\
\text { - Harddisk 500GB Cache 32MB SATA II } \\
\text { - 2x Intel Gigabit NIC 10/100/1000 } \\
\text { - PSU 800W }\end{array}$ & 2 & $\$ 1500$ & $\$ 3.000$ \\
\hline $\begin{array}{l}\text { Router } \\
4 \text { port } 10 / 100 \text { dan Print server }\end{array}$ & 1 & $\$ 85$ & $\$ 85$ \\
\hline $\begin{array}{l}\text { Modem } \\
-1 \text { x RJ-45 } \\
-1 \text { x 2-contact clip type terminal }\end{array}$ & 1 & $\$ 157$ & $\$ 157$ \\
\hline $\begin{array}{l}\text { Switch } \\
-16 \text { Port } 10 / 100 \text { Ethernet }\end{array}$ & 3 & $\$ 80$ & $\$ 240$ \\
\hline
\end{tabular}

b) B. Rincian Perkiraan Biaya Usulan Aplikasi

Tabel 3 Perkiraan Pembelian Aplikasi

\begin{tabular}{lrr}
\hline Aplikasi & Biaya(\$) \\
\hline Website & & $\$ 500$ \\
E-CRM & $\$ 1,000$ \\
Survey System & & $\$ 500$ \\
EIS & & $\$ 3,000$ \\
\hline \multicolumn{1}{c}{ Total Biaya(\$) } & $\mathbf{\$ 5 , 0 0 0}$ & \\
\hline
\end{tabular}

Portfolio Aplikasi Masa Mendatang

Tabel 4 Portfolio Aplikasi Masa Mendatang pada PT. Microsis

\begin{tabular}{ll}
\hline Strategic & High Potential \\
\hline & EIS \\
& MIS \\
\hline
\end{tabular}




\begin{tabular}{ll}
\hline Key Operational & Support \\
\hline Sistem Informasi Penjualan & Sistem Informasi Akuntansi \\
Sistem Informasi Pembelian & Survey System \\
Sistem Informasi Persediaan & \\
E-CRM & \\
\hline
\end{tabular}

\section{SIMPULAN}

Berdasarkan analisis perencanaan strategi sistem dan teknologi informasi pada PT. Microsis, dapat ditarik simpulan sebagai berikut :

1. Berdasarkan analisis pada lingkungan eksternal bisnis perusahaan, dapat disimpulkan bahwa tingkat persaingan bisnis yang kian meningkat menjadikan perusahaan untuk harus bisa meningkatkan strategi bisnis agar bisa bersaing dengan perusahaan sejenis lainnya.

2. Berdasarkan analisis lingkungan internal bisnis perusahaan dapat diketahui bahwa perusahaan harus bisa memanfaatkan kekuatan serta peluang yang dimiliki nya agar dapat mempertahankan eksitensinya dalam pasar IT Solution.

3. Berdasarkan analisis pada lingkungan eksternal dan internal SI/TI perusahaan dapat dilihat bahwa perusahaan belum memiliki sistem informasi yang cukup baik untuk mendukung proses bisnis perusahaan: erlu dilakukan pengembangan sistem untuk mendukung sepenuhnya proses bisnis perusahaan agar dapat merealisasikan pencapaian tujuan strategis jangka pendek dan jangka panjang perusahaan.

\section{DAFTAR PUSTAKA}

Grant, Robert M. (2002). Strategic Management. Cetakan ke-3. Jakarta: Elex Media Komputindo.

Indrajit, R. E., (2001). Manajemen Sistem Informasi dan Teknologi Informasi. Jakarta: Elex Media Komputindo.

Pollack, T. A., (2010), Strategic Information Systems Planning, ASCUE Proceedings: 47-58, The 43rd Annual ASCUE Conference, South Carolina

Rangkuti, Freddy. (2006). Analisis SWOT Teknik Membedah Kasus Bisnis. Jakarta: PT. Gramedia Pustaka Utama.

Turban, E. R., Rainer, R. K., \& Potter, R. E. (2003). Introduction To Information Technology. Second Edition. John Wiley \& Sons, Inc.

Ward, J., \& Peppard, J. (2002). Strategic Planning For Information System. ${ }^{\text {rd }}$ Edition. John Willey \& Sons. 